\title{
Effects of Amount of Glass Fiber Laminate Skins in Sandwich Composite of Filled Core
}

\author{
João Pedro Monteiro Cheloni ${ }^{a *}$, Marcio Eduardo Silveira ${ }^{a}$, Leandro Jose da Silva ${ }^{b}$ \\ ${ }^{a}$ Laboratório de Simulação Numérica Aplicada, Departamento de Engenharia Mecânica, Universidade \\ Feradal de São João Del Rei-UFSJ, CEP 36.307-352, São João Del Rei, MG, Brasil \\ ${ }^{b}$ Centro de Inovação Tecnológica em Materiais Compósitos, Departamento de Engenharia Mecânica, \\ Universidade Federal de São João Del Rei - UFSJ, CEP 36.307-352, São João Del Rei, MG, Brasil
}

Received: January 10, 2018; Revised: August 28, 2018; Accepted: October 01, 2018

\begin{abstract}
The purpose of this work is the study of the mechanical behavior of two different sandwich composite in static and fatigue analysis of three-point bending, using different amount of glass fiber laminated as skins, remaining with same total thickness. The specimens are composed of glass fiber cloth and epoxy resin. The static tests provided the mechanical properties used in numerical simulations as well as fatigue tests analysis. Applying controlled displacement, it was analyzed load reactions, lifetime and failure modes during fatigue tests. Identifying the failures modes in microscopic analyses it was perceived adhesive fracture in fiber/matrix as first damage and core rupture as ultimate damage.
\end{abstract}

Keywords: Sandwich Composite, Mechanical Properties, Numerical Simulation, Fatigue, Fracture Analysis.

\section{Introduction}

Studies on composite materials reinforced with fibers are becoming more evident every day due to their high applicability in several engineering sectors ${ }^{1,2}$. These materials can exhibit excellent properties due to the possible combination of different materials and fiber orientations, producing structures optimized and specific for certain loads ${ }^{3-6}$. One of the most used material in this context are the sandwich composite materials.

Sandwich composite materials are consisted on a structural plate made of two high strength external skins bonded on a low strength core ${ }^{7}$. The skins withstand the bending stresses and give the structure hardwearing surface whereas light core material carries the shear stresses generated by loads, distributing them over a larger area ${ }^{8,9}$. An advantage of this materials is related to their high strength to weight ratio, being suitable for use in application that require low weight, such as aerospace ${ }^{10}$. The use of glass fiber laminates as skins of sandwich composite provide benefits like best cost/benefit ratio between the reinforcements offered for manufacturing polymer composites ${ }^{11}$. Commonly glass fibers are used in applications that require an increase in strength, but not in high performance due to limitations comparing with carbon fibers ${ }^{12}$.

Failure of laminated composites is a complex phenomenon that involves matrix cracking, delamination and fiber breaking ${ }^{13}$. These failures modes may be even more complex when dealing with sandwich composites, where others failure modes appear as plastic deformation, buckling of skins, wrinkling, and core shear ${ }^{14}$. In the last years some studies

*e-mail: jpedromcheloni@hotmail.com on fatigue behavior of sandwich composite became more evident ${ }^{14,15}$. Due to wide materials combination which can be used to build the core and the faces of the sandwich structure and existence of different types of fatigue tests this field of knowledge still open to news studies. Epoxy resins currently stands out among the thermosets due to their performance and high applicability, as in fiber reinforced materials ${ }^{16}$. The high viscosity of these resins at room temperature allows good adhesion and formability to complex surfaces ${ }^{17}$.

The fatigue behavior of sandwich beams under three point bending were performed by Mahi et al. ${ }^{18}$ They used laminated $[0 / 90]_{\mathrm{s}}$ glass fiber skins and foam core. The degradation and concept of fatigue modulus was introduced to predict the life of composite material. During fatigue loading, the stress-strain curve reflects the reduction in the modulus. Bey at al. ${ }^{14}$ showed a transition between failure modes in sandwich beams under fatigue loading highlighting the transition of shear failure of core to the tensile failure of face laminate as function of loading amplitude. Belingardi el al. ${ }^{8}$ showed that to establish the magnitude of the reduction in the fatigue life is a fairly difficult task because defects caused by manufacturing processes, such as core damage, interface debonding. Burman et al. ${ }^{19}$ proposed a simple approach to determine the fatigue life of sandwich components where damage are presents based on the reduction of the fatigue strength of the undamaged component by means of a multiplying factor.

It is important to know the fatigue behavior of laminated used as face skins of sandwich structures because normally its receive the highest loads ${ }^{20,21}$. Studying the fatigue behavior in glass fibers non-crimp-fabric (NCF) laminates reinforced epoxy, Gagel et al. ${ }^{22,23}$ realized the formation of cracks and stiffness degradation subjected to tensile fatigue loading and concluded that some of the micro-crack formation processes 
are the same as under quasi-static loading. Aono el al. ${ }^{24}$ performing fatigue tests at stress ratio $\mathrm{R}=-1$ and $\mathrm{R}=0,1$ on [ $+45 /-45]$ glass fibers NCF laminates observed higher fatigue life for lower stress ratio and different failure modes.

In this context it becomes important to identify the influence of the use of different amounts of layers on fatigue behavior in sandwich composite mainly in bending loads, because this would result in optimized composites besides allowing reduction of weight and cost. In this work the fatigue life was determined for two different sandwich composites highlighting the influence of using different amounts of glass fibers laminate as skins remaining the same total thickness of the sandwich. The sandwiches were manufactured using a simple core of epoxy resin and a laminated [0/90] woven glass fibers skins. The study was based on experimental analysis and numerical simulation, under static and dynamic bending loading. Microscopic analysis was performed in different stages to understand the characteristic of fracture mechanics.

\section{Materials and Methods}

\subsection{Materials - reinforcement and resin}

To accomplish the study, two different sandwich composites laminated were created. It was used as skins of sandwich, plain weave glass-fiber cross-ply [0/90] $\left(200 \mathrm{~g} / \mathrm{m}^{2}\right)$ supplied by Owens Corning-Brazil and epoxy resin Renlam M using hardener Aradur HY 951 provided by Huntsman-Brazil. The core was filled with the same epoxy resin. The difference between sandwiches are given by the thickness of the laminate and core, where both have total thickness of $3 \mathrm{~mm}$, but one sandwich composite using three layers (SC3L) and the other one using five layers (SC5L).

\subsection{Manufacturing of sandwich composite}

Firstly, two laminates shins, one with three layers and other with five layers, were performed by manual lamination manufacturing (hand lay-up) where the epoxy resin mixed with hardener (10:1 weight ratio), was homogeneous spread over each layer obtaining volumetric fraction $40 \%$ fibers. Soon after, the vacuum bag lamination process, was conducted on flat mold at room temperature, with $75 \mathrm{KPa}$, obtaining resin compaction and distribution. After seven days curing at room temperature, part of the laminated was separated to obtain at least five specimens for each mechanical test and another part was separated to prepare the sandwich composite.

The sandwich composites were performed using a particular thickness mold between the skins for each laminate in order to obtain the same total thickness for both sandwiches. The process consists in put the mold with closed side edges above a part of laminate, filling until the top edges with epoxy resin and put another part of laminate over it with a distributed pressure of $4 \mathrm{KPa}$ during the cure at room temperature. Soon after the mold was removed and the specimens were produced. The idea of using a core filled with epoxy resin is due to ease of construction and provide better adhesion between core and face, necessary especially for failure analysis in the fatigue tests.

\subsection{Tensile and flexural tests}

The uniaxial tensile tests were performed in each material of the sandwich composite individually using Universal Mechanical Test Machine SHIMADZU AG-X Plus, Figure 1. For laminate faces, five specimens were analyzed according to ASTM D3039 ${ }^{25}$ standard using 3 layers with dimensions $0.55 \mathrm{~mm}$ thickness, $25 \mathrm{~mm}$ width and $250 \mathrm{~mm}$ length using tabs at the ends of the specimens. It was used cross-head speed $2 \mathrm{~mm} . \mathrm{min}^{-1}$ with room temperature $25^{\circ} \mathrm{C}$. The dimensions have tolerances of $1 \%$. For epoxy resin five specimens created using molds, were analyzed according to ASTM D638 ${ }^{26}$ standard with dimensions $165 \mathrm{~mm}$ length $13 \mathrm{~mm}$ width and $3.2 \mathrm{~mm}$ thickness.

The three-point bending test was performed according BS EN 2562 27 Standard for both sandwich composites proposed, Figure 2. It was used the Universal Mechanical Test Machine SHIMADZU AG-X Plus at cross-head speed $2 \mathrm{~mm} \cdot \mathrm{min}^{-1}$. Five specimens for each sandwich composite were analyzed with dimensions $100 \mathrm{~mm}$ length, $10 \mathrm{~mm}$ width and $3 \mathrm{~mm}$ thickness.

\subsection{Bending fatigue tests}

In order to analyze the sandwich composites under cyclic efforts influence, it was used a three-point flat bending fatigue machine, Figure 3, based in ASTM D7774-12 ${ }^{28}$. It uses span of $80 \mathrm{~mm}$, frequency of $14.25 \mathrm{~Hz}$ and provide a stress ratio $\mathrm{R}$ equal to -1 . It was used five specimens of each sandwich composite using sinusoidal wave form with maximum displacement of $2 \mathrm{~mm}$. The tests were performed at room temperature. The reaction efforts in the strain gages are processes by Spider 8 data acquisition and Catman software in real time recognizing force amplitude and life of specimens. The core rupture was taken as limit life value to finish the test.

\subsection{Numerical simulation}

Finite Elements Model was used to analyze the sandwich composite behavior during one cyclic in fatigue test, Figure 4 (a) and Figure 4 (b). The models were discretized using 20000 hexahedron solid elements with $1 \mathrm{~mm}$ size and $1^{\text {st }}$ order shape function through Hypermesh software. As it was used small displacement, small thickness, cross-ply glass fiber cloth and the efforts in bending fatigue generate only axial stresses, the material models were considered isotropic to simplify the solver inputs. Sandwich plate can be considered isotropic when the core is made of an isotropic or transversely isotropic material and the top and bottom skins are made of identical isotropic materials or 


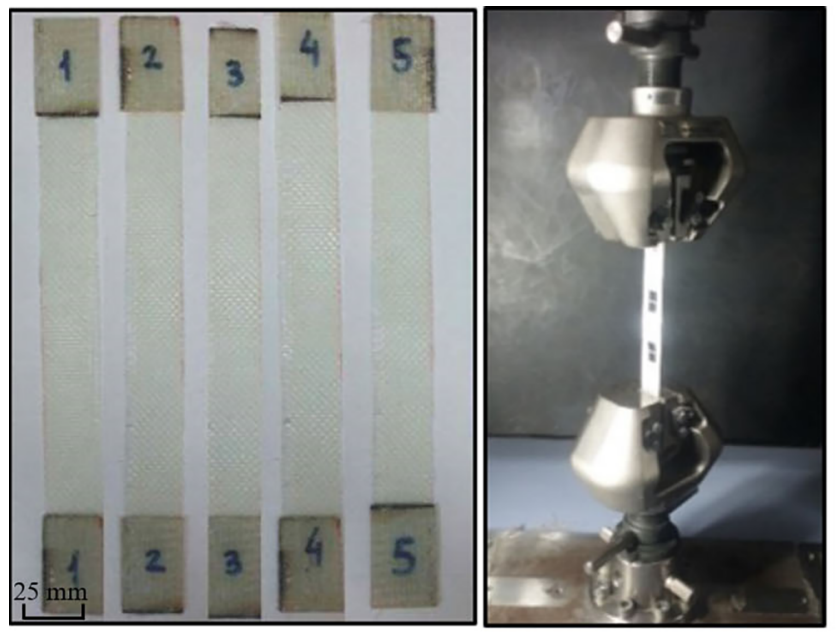

(a)

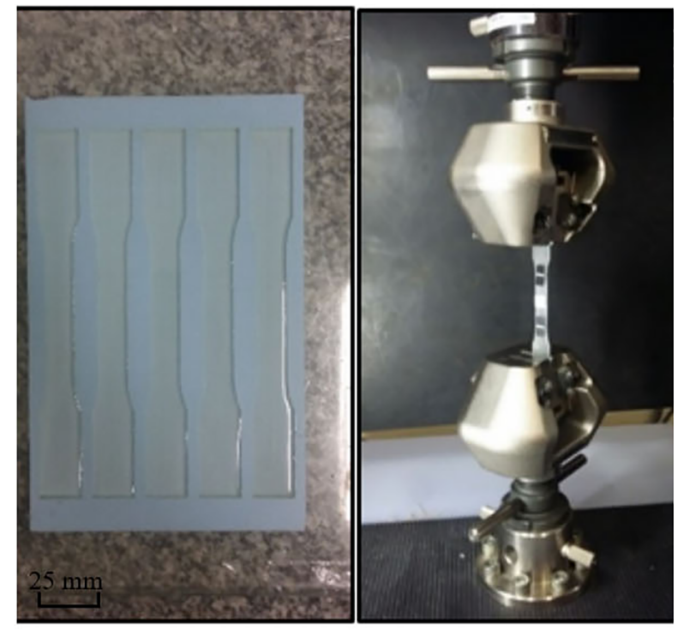

(b)

Figure 1. Tensile test (a) laminated and (b) epoxy resin
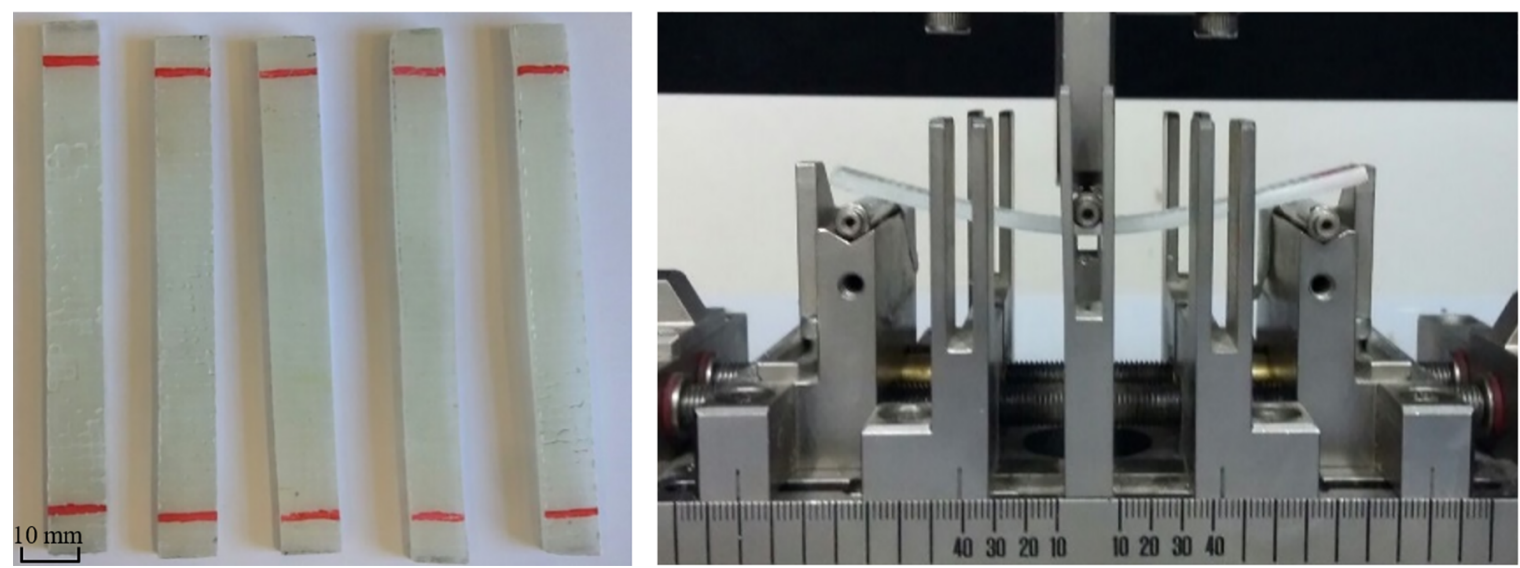

Figure 2. Flexural test of sandwich composite specimens.

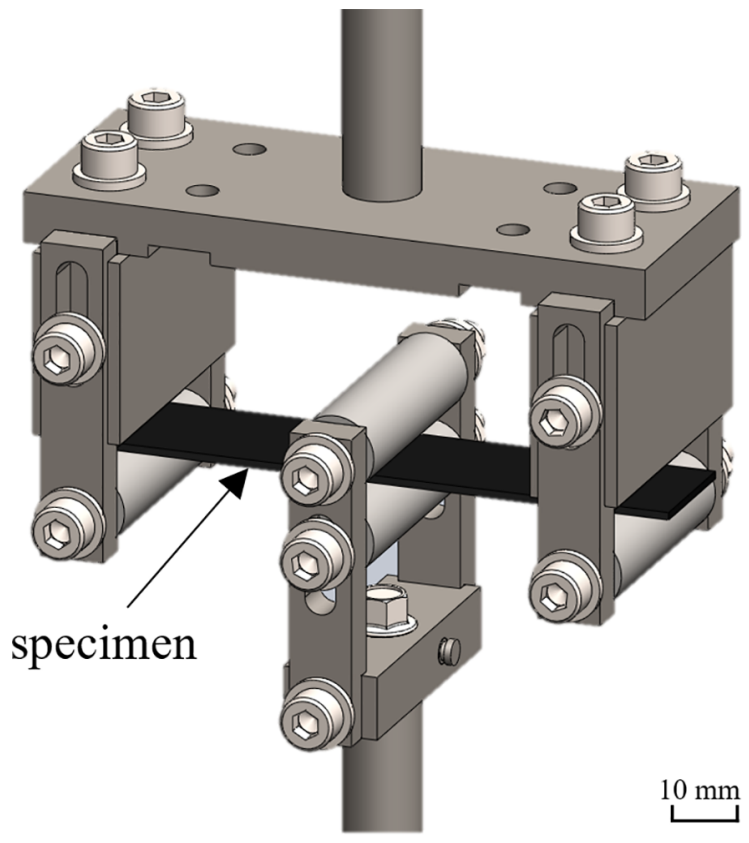

are identical quasi-isotropic laminates ${ }^{29}$. Contact surface was created between sandwich composite elements and cylindrical support surface, Figure 4 (c). The simulations were carried out using the RADIOSS software, which has a robust explicit formulation to simulate nonlinearities from the contact. A vertical displacement of $2 \mathrm{~mm}$ was imposed on the central support, ensuring remained stress within the elastic regime. The results were analyzed using HyperView, identifying stress distribution in the specimens.

\subsection{Fractures analysis}

A qualitative analysis of the specimens was performed in order to observe the reason for the loss of resistance of the material during the fatigue tests. This analysis was made in two stages, at the beginning of the failure and after the complete failure of the material. The specimens were examined microscopically through the Scanning Electron Microscope HITACHI TM 3000.

Figure 3. Three-point fatigue machine mechanism 


\section{Results and Discussion}

\subsection{Mechanical properties - tensile and flexural tests}

Mechanical behavior related to tensile tests of epoxy resin and cross-ply glass fiber laminate are shown from the stress-strain diagram, Figure 5. It can be observed a sudden failure in both materials. The epoxy resin shows average strain values around $4 \%$ e $5 \%$ with linear elastic modulus until $40 \%$ of tensile strength, while the laminate shows less deformation, $2 \%$ and linear elastic modulus until the final failure of the material.

The average values of tensile modulus and tensile strength of epoxy resin and cross-ply glass fiber laminate as well as respective standard deviation are shown in the Table 1.

The Load $x$ Displacement diagram during three-point bending is shown in Figure 6, for both sandwich composite,
Table 1. Mechanical properties- woven glass fiber laminate and epoxy resin - tensile test

\begin{tabular}{lcc}
\hline \multicolumn{3}{c}{ Mechanical Properties } \\
\hline Material & $\begin{array}{c}\text { Tensile Strength } \\
\text { (MPa) }\end{array}$ & $\begin{array}{c}\text { Elasticity Modulus } \\
\text { (GPa) }\end{array}$ \\
\hline Woven Glass & & \\
Fiber laminate & $329.15 \pm 30.07$ & $16.14 \pm 2.09$ \\
Epoxy resin & $19.08 \pm 2.02$ & $1.60 \pm 0.20$ \\
\hline
\end{tabular}

SC3L and SC5L. It is possible to observe a linear behavior during the test with superior flexural properties of the sandwich composite for SC5L.

Observing the Table 2, the Elasticity Modulus of SC5L is superior $34.96 \%$ when compared with $\mathrm{SC} 3 \mathrm{~L}$ and the Flexural Strength is almost the same due to no difference in total thickness.

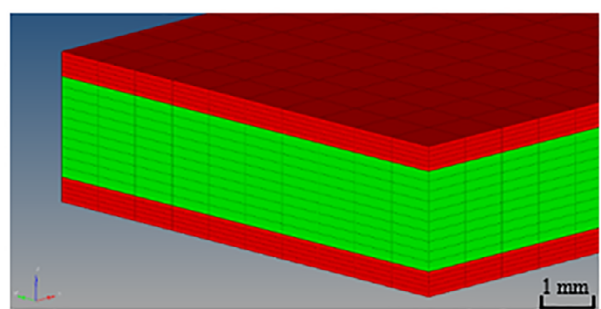

(a)

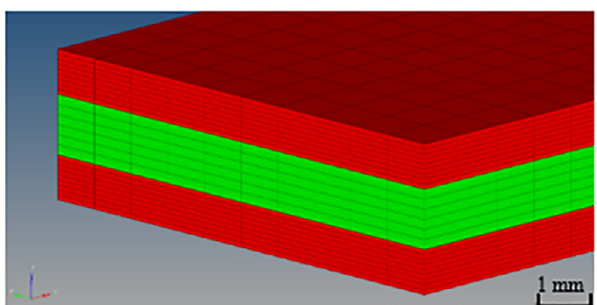

(b)

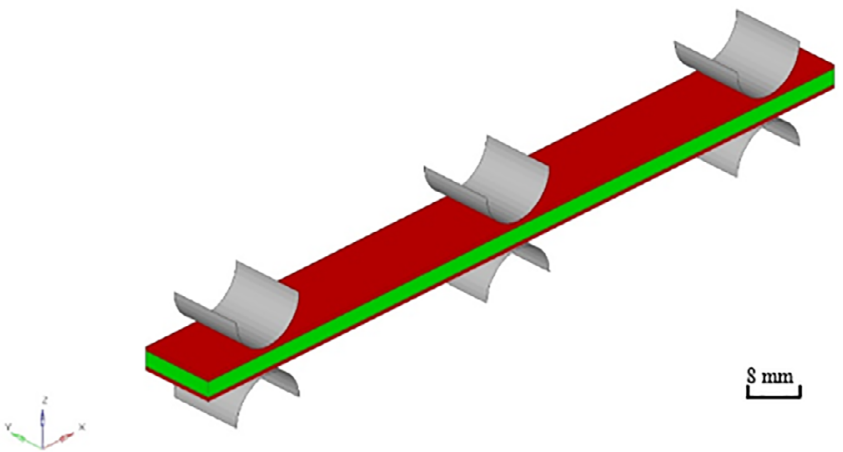

(c)

Figure 4. Finite Elements Model of the specimens, (a) SC3L and (b) SC5L and (c) three-point bending supports.

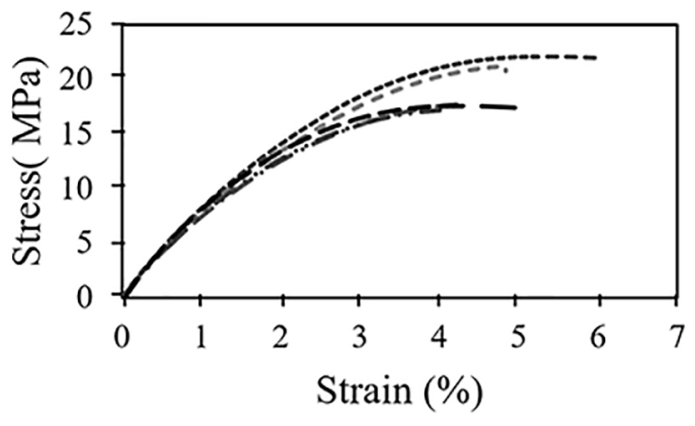

(a) epoxy resin

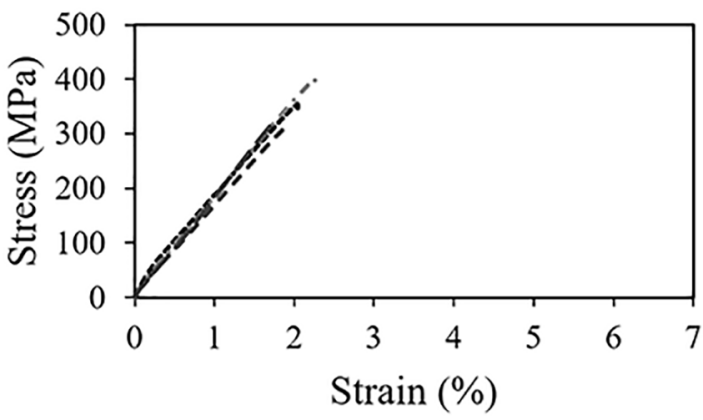

(b) glass fiber laminate

Figure 5. Stress $x$ Strain diagram in tensile test (a) Epoxy resin; (b) Glass fiber laminate. 


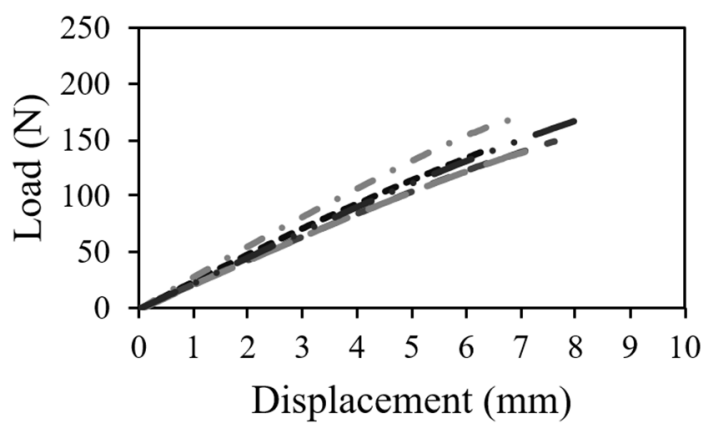

(a) $\mathrm{SC} 3 \mathrm{~L}$

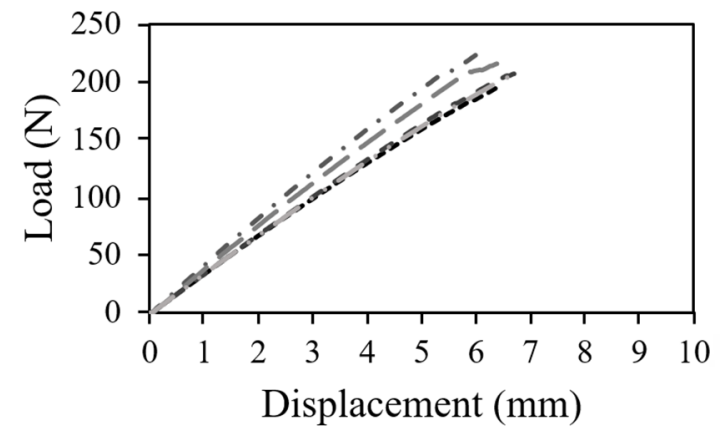

(b) $\mathrm{SC} 5 \mathrm{~L}$

Figure 6. Load x Displacement diagram in flexural test (a) SC3L; (b) SC5L.

Table 2. Mechanical properties- sandwich composite laminate flexural test

\begin{tabular}{lcc}
\hline & \multicolumn{2}{c}{ Mechanical Properties } \\
\hline Material & $\begin{array}{c}\text { Flexural Strength } \\
\text { (MPa) }\end{array}$ & $\begin{array}{c}\text { Elasticity Modulus } \\
\text { (GPa) }\end{array}$ \\
\hline SC3L & $292.76 \pm 5.30$ & $12.70 \pm 1.10$ \\
SC5L & $293.43 \pm 5.80$ & $17.14 \pm 0.83$ \\
\hline
\end{tabular}

\subsection{Numerical simulation}

From the results obtained by static tests it was possible to perform numerical simulation, getting results of stress $\left(\sigma_{\mathrm{xx}}\right)$ along thickness for SC3L and SC5L as shown in Figure 7. As expected, the highest stress values are in outer layers and decreases as it approaches to the core center. It can be note low maximum stress in the core, $2 \mathrm{MPa}$ to SC3L and 4 $\mathrm{MPa}$ to SC5L. The large difference in the elastic modulus between core and skins provided skins stress around $90 \mathrm{MPa}$ in both sandwiches.

The Figure 8 shows the stress distribution during half cycle in fatigue tests for SC3L and SC5L respectively, which can be highlighted a higher stress during compression due to contact stress.

The numerical model used in the simulations shows stress coming from an equivalent elasticity modulus of laminated skins. It does not provide detailed stress of interface regions.

\subsection{Fatigue results}

The reaction load and number of cycles with respective standard deviation were studied for each sandwich composite and are shown on Table 3. The monitored of reaction load allowed collect the bending stiffness of the specimens and information about possible crack propagation, fibers rupture and delamination that reduce the sandwich structural properties with fatigue cycling.

It was possible to note, although the SC5L contains higher amounts of fiberglass, this does not ensure a longer life in fatigue, but certainly higher load reaction. The specimens of SC5L showed slightly lower fatigue lifetime than SC3L.

The fatigue failure of sandwich composites occurred around $6 \mathrm{e}+05$ cycles applying $30 \%$ of the ultimate tensile strength. Despite good approach when assuming homogenous materials in the static test simulation, it is important in the dynamic tests to analyze the stress in the regions of interface fiber/matrix.

\section{4 Characteristic of mechanical fracture- fatigue tests}

A microscopic analysis of each sandwich composite was performed to verify the failures like delamination and crack propagation in fatigue test. In Figure 9 it is possible to notice a side view of SC3L and SC5L. Although the numerical

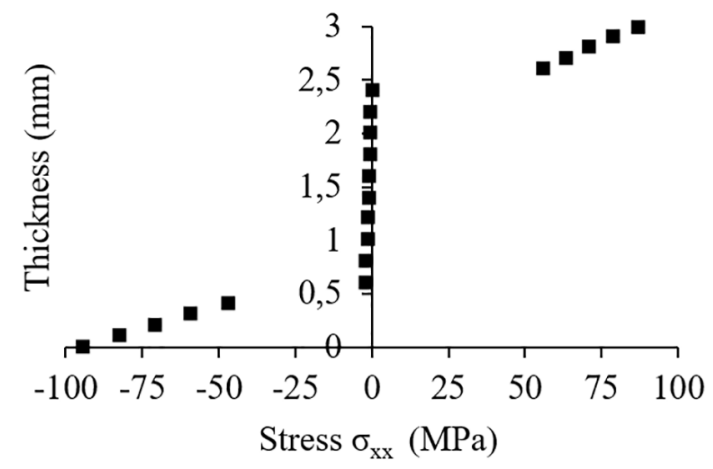

(a) $\mathrm{SC} 3 \mathrm{~L}$

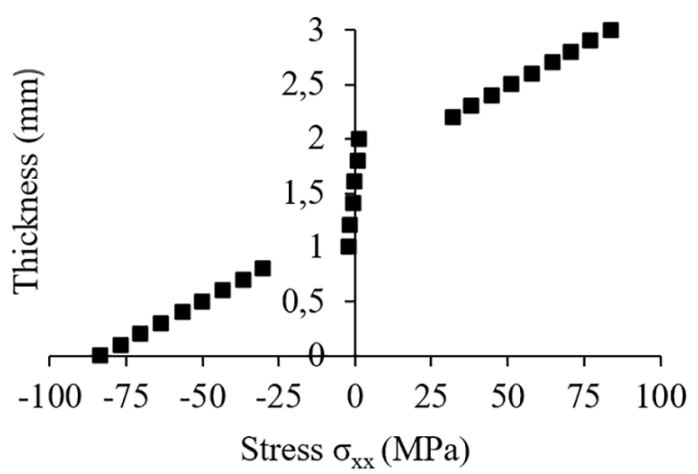

(b) $\mathrm{SC} 5 \mathrm{~L}$

Figure 7. Stress x Thickness for (a)SC3L; (b) SC5L. 


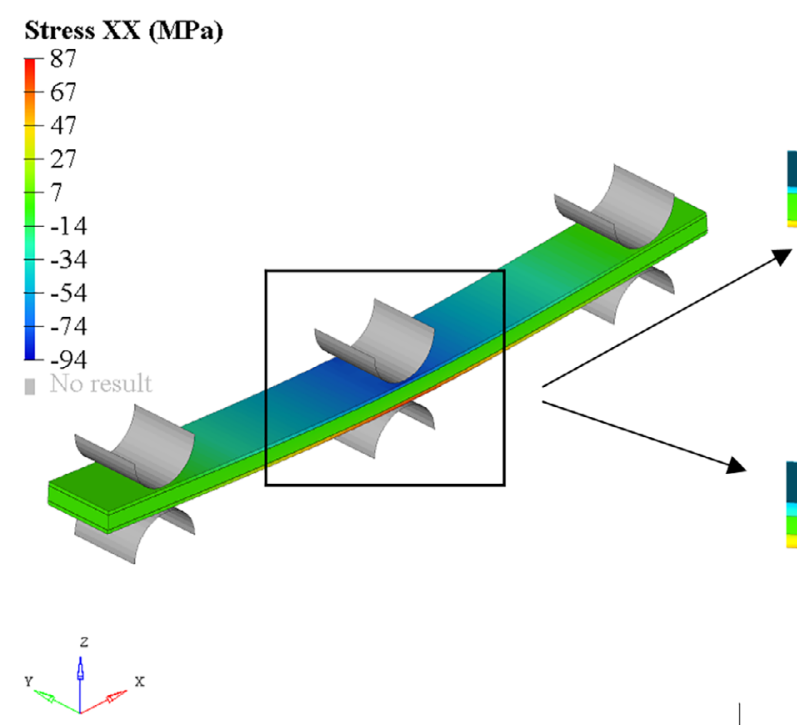

Figure 8. Stress $\left(\sigma_{\mathrm{XX}}\right)$ distribution in numerical simulation for (a) SC3L and (b) SC5L.

Table 3. Results of fatigue tests

\begin{tabular}{lcc}
\hline Material & Load $(\mathrm{N})$ & Number of cycles \\
\hline$S C 3 L$ & $57 \pm 3$ & $6.82 E+05 \pm 4.79 E+04$ \\
$S C 5 L$ & $77 \pm 3.60$ & $6.13 E+05 \pm 8.90 E+04$ \\
\hline
\end{tabular}

simulation results show higher stresses on the outer skins of the sandwich, through the microscopic analysis of the beginning failure it is possible to observe in the middle skins, the adhesive fracture of fiber/matrix. Similar results were obtained by Beyene and Belingardi ${ }^{30}$. This fracture occurs specifically on the resin of the fibers perpendicular to length.

When the final failure occurs, the crack propagated completely in the core, Figure 10. At this moment some fibers have already broken but the remaining fibers still holding the material together. Furthermore, it can be observed more expressive damage in SC5L as delamination between core and skins, total core rupture losing cohesion.

Macroscopically, the specimens exhibit a whitened area in fracture region, Figure 11, located in the cross-section of specimens, near the central support. This area, characterized by fracture adhesive, can also be seen in static bending tests, as shown in the work developed by Felipe et $\mathrm{al}^{6}$ and Chemami et $\mathrm{al}^{31}$, representing crack locations in the matrix.

\section{Conclusion}

Through the experimental analysis (static and fatigue bending) and the numerical simulation of two configurations of sandwich composites, the main conclusion are obtained as follows:

- Despite the use of higher amount of glass fibers in SC5L, static tests showed the same flexural strength between SC5L and SC3L. However, the Elasticity Modulus increased 34,96\%.

- Although the numerical simulation indicated a maximum stress in the lower and upper skins laminated, it was observed by microscopic analysis that the crack began inside the laminate in fiber/ matrix interface for both sandwiches.

- $\quad$ Regarding the fatigue tests, SC3L presented slightly better lifetime than SC5L using the same displacement, although the reaction efforts of SC5L was higher.

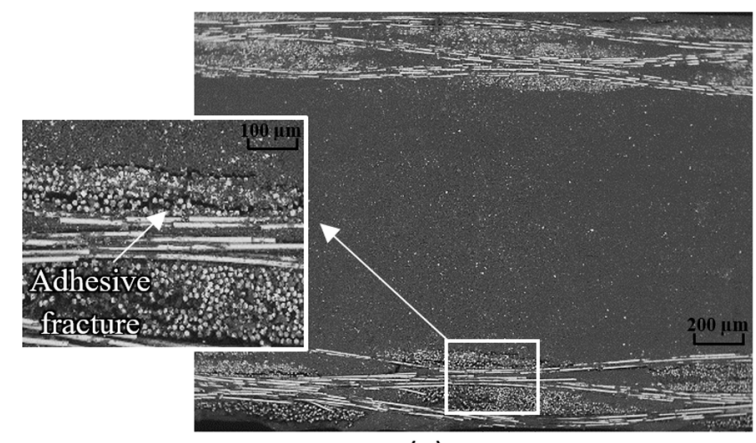

(a)SC3L

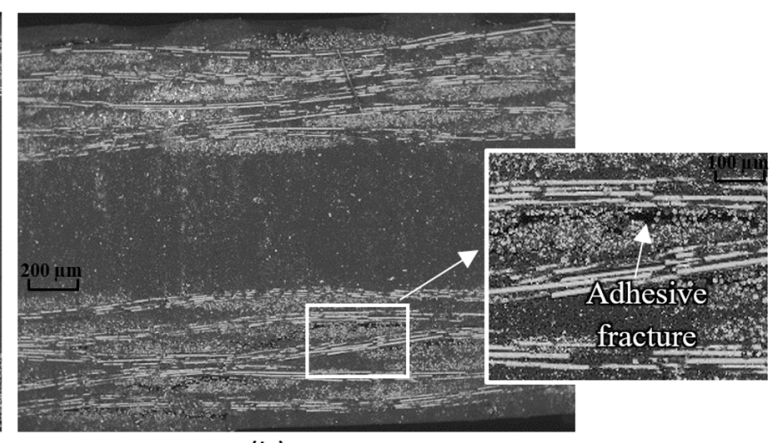

(b) SC5L

Figure 9. Beginning of failure inside the laminate for (a) SC3L and (b) SC5L 


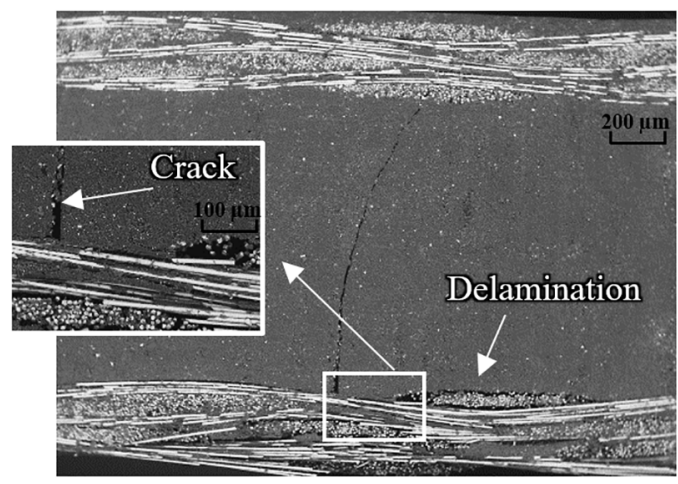

(a)SC3L

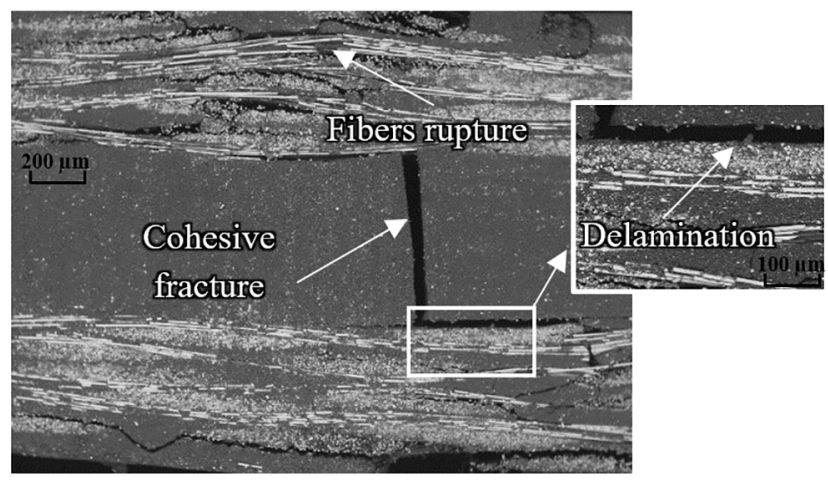

(b) SC5L

Figure 10. Final failure of sandwich composites (a) SC3L and (b) SC5L

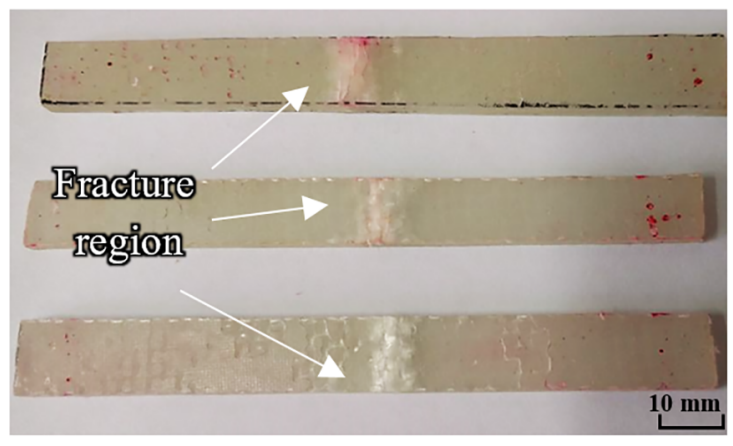

Figure 11. Fracture characteristic in the cross-section

- Through the fracture analysis, noted that both sandwich composite during fatigue tests, presented adhesive fracture on the resin of the fibers perpendicular to length as first stage of failure. After the end of the fatigue test, common types of damage such as delamination, fibers rupture, cracks were observed in both sandwiches, mainly in the SC5L.

\section{Acknowledgements}

The authors would like to thank the Brazilian Research Agencies CAPES for the financial supported provided.

\section{References}

1. Callister WD Jr. Materials Science and Engineering: An Introduction. 7th ed. New York: John Wiley \& Sons; 2007.

2. Luz SM, Costa SM, Gonçalves AR, Del'Arco Junior AP, Costa AS. Polypropylene Composites Reinforced with Biodegraded Sugarcane Bagasse Fibers: Static and Dynamic Mechanical Properties. Materials Research. 2016;19(1):75-83.

3. Zenkert D, ed. The Handbook of Sandwich Construction. Engineering Materials Advisory Services Publishing; 1997.

4. Cheloni JPM, Silveira ME. Analytical and numerical analysis of laminated composite tubes. In: Proceedings of the 3rd Brazilian Conference on Composite Materials-BCCM3; 2016 Aug 28-31; Gramado, RS, Brazil.
5. Sevkat E, Tumer H, Kelestemur M, Dogan S. Effect of torsional strain-rate and lay-up sequences on the performance of hybrid composite shafts. Materials \& Design. 2014;60:310-319.

6. Felipe RCTS, Felipe RNB, Batista ACMC, Aquino EMF. Polymer Composites Reinforced with Hybrid Fiber Fabrics. Materials Research. 2017;20(2):555-567.

7. Mendonça PTR. Materiais Compostos \& Estruturas - Sanduiche. 1a ed. São Paulo: Manole; 2005.

8. Belingardi G, Martella P, Peroni L. Fatigue analysis of honeycomb-composite sandwich beams. Composites Part A: Applied Science and Manufacturing. 2007;38(4):1183-1191.

9. Mantari JI, Soares CG. Generalized layer wise HSDT and finite element formulation for symmetric laminated and sandwich composite plates. Composite Structures. 2013;105:319-331.

10. Gibson RF. Principles of Composite Material Mechanics. Boca Raton: CRC Press; 2007.

11. Marinucci G. Materiais Compósitos Poliméricos - Fundamentos e Tecnologia. 1a ed. São Paulo: Artliber; 2011.

12. Santos JC, Vieira LMG, Panzera TH, Shiavon MA, Christoforo AL, Scarpa F. Hybrid glass fibre reinforced composites with micro and poly-diallyldimethylammonium chloride (PDDA) functionalized nano silica inclusions. Materials \& Design (1980-2015). 2015;65:543-549.

13. Cao Y, Cameron J. Flexural and Shear Properties of Silica Particle Modified Glass Fiber Reinforced Epoxy Composite. Journal of Reinforced Plastics and Composites. 2006;25(4):347-359.

14. Bey K, Tadjine K, Khelif R, Chemami A, Benamira M, Azari Z. Mechanical Behavior of Sandwich Composites Under ThreePoint Bending Fatigue. Mechanics of Composite Materials. 2015;50(6):747-756.

15. Zenkert D, Burman M. Failure mode shifts during constant amplitude fatigue loading of GFRP/foam core sandwich beams. International Journal of Fatigue. 2011;33(2):217-222.

16. Jin FL, Li X, Park SJ. Synthesis and application of epoxy resins: A review. Journal of Industrial and Engineering Chemistry. 2015;29:1-11.

17. Levy Neto F, Pardini LC. Compósitos Estruturais: Ciência e Tecnologia. São Paulo: Edgard Blücher; 2006. 
18. El Mahi A, Khawar Farooq M, Sahraoui S, Bezazi A. Modeling the flexural behavior of sandwich composite materials under cyclic fatigue. Materials \& Design. 2004;25(3):199-208.

19. Burman M, Zenkert D. Fatigue of Undamaged and Damaged Honeycomb Sandwich Beams. Journal of Sandwich Structures \& Materials. 2000;2(1):50-74.

20. Wang Z, Xu L, Sun X, Shi M, Liu M. Fatigue behavior of glass-fiber-reinforced epoxy composites embedded with shape memory alloy wires. Composite Structures. 2017;178:311319.

21. Roundi W, El Mahi A, El Gharad A, Rebiere JL. Experimental Investigation of the fatigue behavior of glass/epoxy composites evaluated by the stiffness degradation and damage accumulation. Journal of Composite Materials. 2018;1-10. DOI: $10.1177 / 0021998318790341$

22. Gagel A, Lange D, Schulte K. On the relation between crack densities, stiffness degradation, and surface temperature distribution of tensile fatigue loaded glass-fibre non-crimpfabric reinforced epoxy. Composites Part A: Applied Science and Manufacturing. 2006;37(2):222-228.

23. Gagel A, Fiedler B, Schulte K. On modelling the mechanical degradation of fatigue loaded glass-fibre non-crimp fabric reinforced epoxy laminates. Composites Science and Technology. 2006;66(5):657-664.
24. Aono Y, Noguchi H, Lee SH, Kuroiwa T, Takita K. Fatigue strength of double-bias mat composites composed of stitched unit layers. International Journal of Fatigue. 2006;28(10):1375-1381.

25. ASTM International. ASTM D3039 / D3039M-14 - Standard Test Method for Tensile Properties of Polymer Matrix Composite Materials. West Conshohocken: ASTM International; 2014.

26. ASTM International. ASTM D638-14 - Standard Test Method for Tensile Properties of Plastics. West Conshohocken: ASTM International; 2014.

27. European Committee for Standardization. BSEN 2562:1997- Carbon fibre reinforced plastics. Unidirectional laminates. Flexural test parallel to the fibre direction. Brussels: European Committee for Standardization; 1997.

28. ASTM International. ASTM D7774-12 - Standard Test Method for Flexural Fatigue Properties of Plastics. West Conshohocken: ASTM International; 2012.

29. Kollár LP, Springer GS. Mechanics of Composite Structures. Cambridge: Cambridge University Press; 2003.

30. Beyene AT, Belingardi G. Bending fatigue failure mechanisms of twill fabric E-Glass/Epoxy composite. Composite Structures. 2015;122:250-259.

31. Chemami A, Bey K, Gilgert J, Azari Z. Behaviour of composite sandwich foam-laminated glass/epoxy under solicitation static and fatigue. Composites Part B: Engineering. 2012;43(3):1178-1184. 